Portland State University

PDXScholar

\title{
Preternatural Rhythm: A Vernacular Application of the Systemic Grid With Respect to the Influence of Organic Processes
}

Mark Richardson Smith

Portland State University

\section{Recommended Citation}

Smith, Mark Richardson, "Preternatural Rhythm: A Vernacular Application of the Systemic Grid With Respect to the Influence of Organic Processes" (1997). Dissertations and Theses. Paper 5828.

https://doi.org/10.15760/etd.7699

This Thesis is brought to you for free and open access. It has been accepted for inclusion in Dissertations and Theses by an authorized administrator of PDXScholar. Please contact us if we can make this document more accessible: pdxscholar@pdx.edu. 


\section{THESIS APPROVAL}

The abstract and thesis of Mark Richardson Smith for the Master of

Fine Arts in Art: Painting were presented June 2, 1997 and

accepted by the thesis committee and the department.

COMMITTEE APPROVALS:

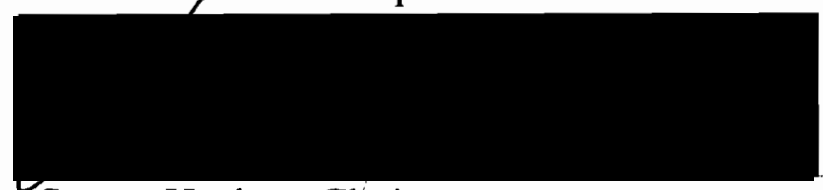

Susan Harlan, Chair

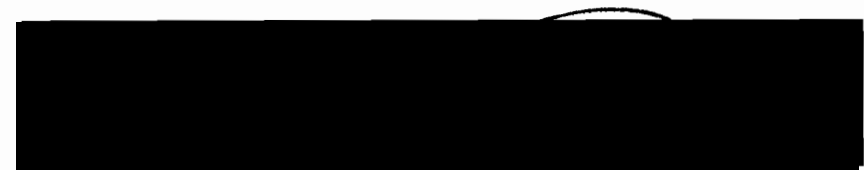

Michihiro Kosuge

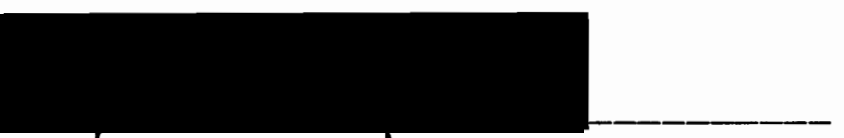

Jahe Kristof

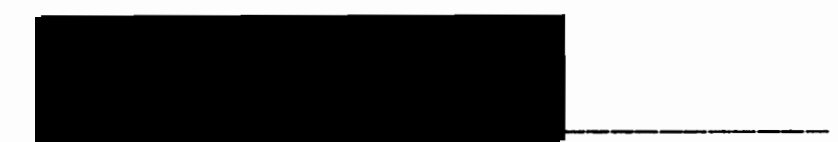

Rachel Hibbard

DEPARTMENT APPROVAL

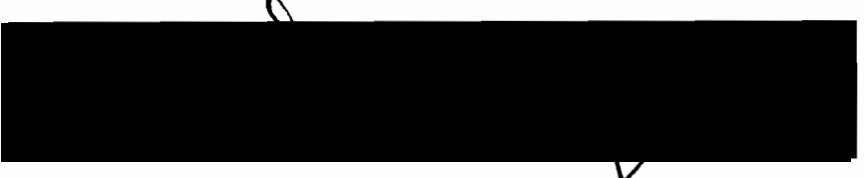

Gregory Goekjian

Representative of the Office of Graduate Studies

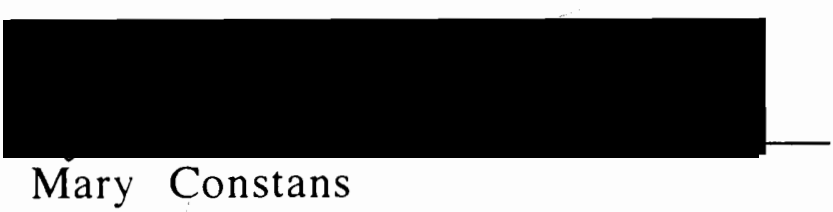

$* * * * * * * * * * * * * * * * * * * * * * * * * * * * * * * * * * * * * * * * * * * * * * * * * * * * * * * * * * * * * * * * * * * * * * *$

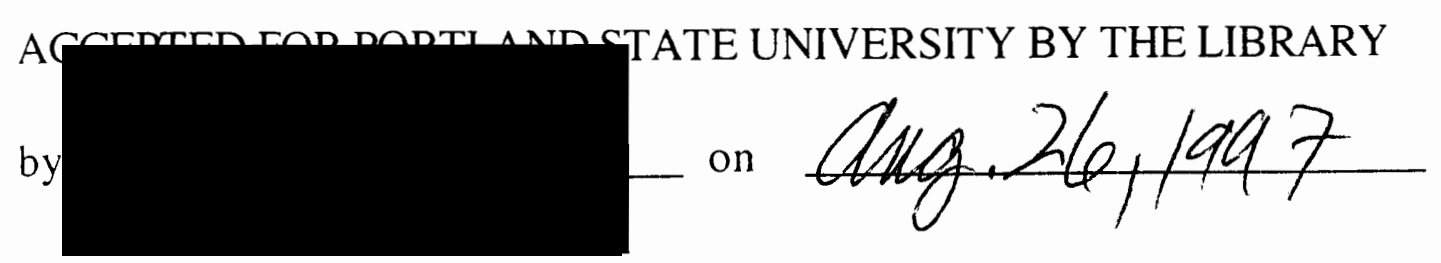




\section{ABSTRACT}

An abstract of the thesis of Mark Richardson Smith for the Master of Fine Arts in Art: Painting presented June 2, 1997.

Title: Preternatural Rhythm: A Vernacular Application of the Systemic Grid With Respect to the Influence of Organic Processes.

The practice of Systemic Art was first introduced under the pretext of Minimal/Conceptual art processes in the 1960s, which incorporated the presentation of empty gridded armatures and self-referential charts, (termed non-relational arrangement) as a means of democratizing esthetic content. Systemic objects stressed industrial fabrication and materials in their manufacture over traditional notions of individualized craft, with the intent to demystify the role of the artist in the creative process. For those reasons, systemic practice has remained highly influential among artists concerned with the public context of aesthetics, although its recent applications have 
gravitated towards incorporation of disparate materials and representational symbols.

With a similar concern for its public context, the exhibition on which this discussion focuses, utilizes gridded formats in combination with discreet materials approaches to individual works that specifically locate the art object's origin within pragmatic and vernacular sources. Those materials include: plastic, recycled newspapers, clipped consumer images, printed fabrics, whole articles of clothing and collected organic substances, arranged in the respective artworks to suggest a sequential reading of the materials evolution, progressing from artificial to natural realms. As symbols connotative of culturally established systems of order, the artwork's gridded formats parallel that materials evolution, becoming ever more fragmented and ultimately dissolute as the images lead to the appearance of organic disarray. 
With an interest in leveling cultural hierarchies, organic processes are brought into context here as a codifying system with which to frame the competing legal, financial, sexual or moral codes of given societies: under the influence of nature, all institutions are subject to obsolescence and decay. To underscore its collective philosophy, this exhibition embraces popular iconography in the belief that its public persona will provide an accessible avenue to private experience, which is still the underlying basis for the realization of the work. In the absence of rendered imagery and individualized markings, private experience is communicated here, through the prevalence of touch as demonstrated through intensive labor practices in the collection and handling of materials. 
PRETERNATURAL RHYTHM:

\title{
A VERNACULAR APPLICATION OF THE SYSTEMIC GRID WITH
}

RESPECT TO THE INFLUENCE OF ORGANIC PROCESSES

b y

MARK RICHARDSON SMITH

A thesis submitted in partial fulfillment of the requirements for the degree of

\author{
MASTER OF FINE ARTS \\ in \\ ART: PAINTING
}

\author{
Portland State University \\ 1997
}




\section{TABLE OF CONTENTS}

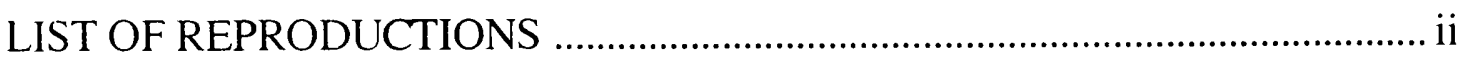

\section{CHAPTER}

I (

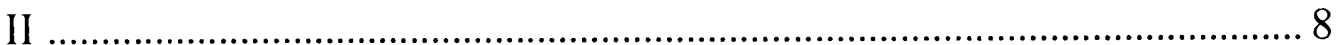

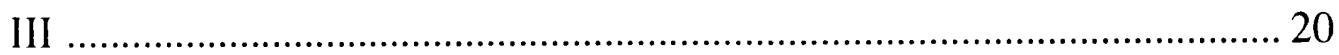

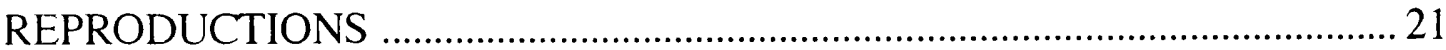

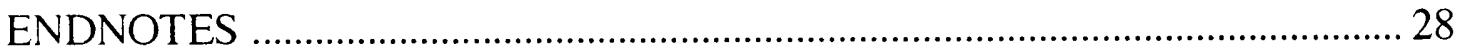

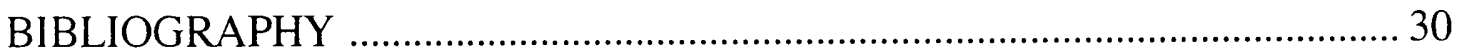




\section{LIST OF REPRODUCTIONS}

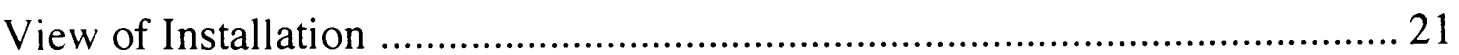

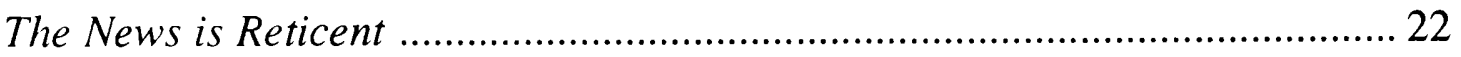

The News is Reticent (detail of newsaper legend) ......................... 23

The News is Reticent (detail bearing impressions of

The Seattle Post-Intelligencer and The Oregonian) .............. 24

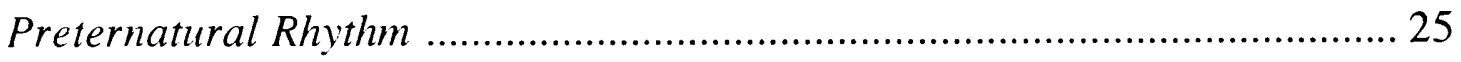

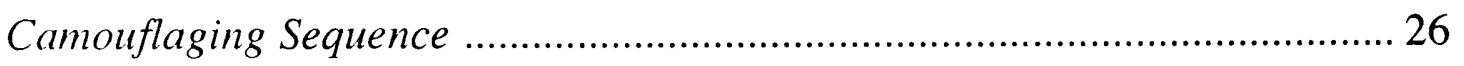

Camouflaging Sequence (detail of organic material) ...................... 27 
This body of work arises out of the collection and compilation of materials originating from both organic and artificial sources-materials already possessing specific associations and histories that continue with their inclusion in the art. The intent is to manipulate those materials within the fictional realm of painting related processes to fully exploit their poetic potential, yet allow for points of access that are grounded in cognitive experience, including the viewer's understanding and familiarity with the source. Through this means, science and aesthetics will share equal prominence in the definition and perception of this work.1

The goal of the exhibition on which this discussion focuses is to present an implied timeline of related works that demonstrate an evolution of images reflecting culturally prescribed systems of order that, when read in sequence, become subject to and reordered by organic processes. Because the idea of culture is so overwhelming, there is an obvious need to codify its experience through a comprehensible structure. With its influence over time, nature provides that comprehensible structure, as it levels all competing hierarchies implicit in the legal, financial, moral or religious codes of given societies: all systems are eventually subject to obsolescence and decay. In the spirit of that natural 
leveling process, the artworks here assume a non-hierarchical bearing, and appear segmented, gridded and/or fractured as they call attention to the multifarious character of lived experience, the gravitational pull of nature and their own material evolution.

The gallery where the artworks are installed is a very linear space that exists in the form of a deep and narrow rectangle. Within that space, the exhibition features three separate works that, when assembled, are similarly proportioned to the horizontal space they occupy. Each is hung on a separate wall. Although considerable margins exist between the works, their horizontal expansiveness suggests a continuum from one work to the next and the viewer is inclined to read them sequentially. The works are respectively titled The News is Reticent, Preternatural Rhythm and Camouflaging Sequence. Each utilizes a unique materials process that would ordinarily be combined with the others into singular paintings. Here, the presentation is such that the art appears dismantled, its successive layers strung side by side along the wall--the effect of the whole suggesting a temporal history of sorts. To underscore this transient quality, the artworks all consist of a base of paper thin fabrics, tissues or clear plastic film and are displayed without structural supports, fastened to the wall at their top margins and allowed to dangle like transparent skins. 
Arranged to read left to right like text, the sequence of the work begins on the left hand wall as the viewer enters the space. The first piece, The News is Reticent, consists of a row of seven sheets of plastic film of equal proportion, each painted a monochromatic hue that surrounds a combination of rectangular, window-like openings (impressions from unfolded newspaper pages) within each surface. This work is followed on the narrow middle wall by Preternatural Rhythm, a tightly composed grid of overlapping, notebook-sized sections of fabric and tissue paper whose central row is superimposed with photographic reproductions of human figures on stationary exercise machines. Because of its extreme horizontality, this work functions like a bridge or conduit between the two larger pieces on the side walls. Camouflaging Sequence, on the right, is the final work in the series and like the other two, is multi-segmented, except that all of its rectangular units vary greatly in size and no longer adhere to a specific grid. Of the three works, it possesses the most physical substance, as it contains not only printed fabrics, but whole articles of clothing, dried flowers, leaves, vines and assorted organic debris that are pressed and layered between ragged stacks of transparent tissue and suspended clothesline style from a long metal carpet rail. With this last piece, the gridded order established in the first two artworks is finally usurped by the organic disarray of the patterned clothing and natural substances. 
For its procedural methodology, this body of work draws upon the influence of Systemic Art which first surfaced as a concept, in discussions specific to Minimal/Conceptual processes and it refers to the predetermined circumstances under which the majority of those works were executed. In the interest of democratizing content, the practice attempted to drain the art object of all humanist expectations through methodical work procedures and industrial fabrication and thereby demystify the role of the artist, placing the creative process within the everyman's realm. Following that logic, grids were the preferred system of order because they implied the usage of charts or informational graphs, absent of any reference other than to their own internal mechanism. This modular, gridded format, referred to by sixties artists as non-relational arrangement, remains an integral structure within contemporary esthetic applications, even though its focus has been considerably altered by the reemergence of representation.

In response to that movement's ideological purity, one of the principle concerns of subsequent generations of artists influenced by minimalism, has been with the issue of promoting difference within its collective philosophy. Over the last ten years, a number of increasingly politicized artists exploring culturally urgent issues such as race, gender and sexuality, have particularly stressed the necessity of private experience as fundamental to bringing the implications of the work into a broader social 
context. Many artists, working with extremely personal issues, have employed gridded arrangements and methodical execution to communicate that sense of difference or multiplicity to the public, including established figures as diverse as Lorna Simpson (combining photography and text in poetic exploration of blacks as the other in a predominately white culture), Renee Green (deconstruction of institutionalized racism through display of existing literature), Leonardo Drew (investigating cultural hybridization by combining ritual materials with minimalist armatures), Tim Rollins and K. O. S. (introducing disenfranchised youth to collaborative art processes based on classic works of literature), Felix Gonzalas-Torres (addressing the AIDS crisis through autobiographical disclosure) and Portia Munson (demystifying female stereotypes through the collection and presentation of feminine kitsch).2

Although not overtly political, the work in this exhibition shares a desire to connect its aesthetics with a more pragmatic application, directly rooted in mainstream culture. And it embraces popular iconography in the belief that a public persona will provide an avenue to a more intimate and enriching experience. Its preoccupation with organic materials demonstrates a willingness to present an overview of that diverse cultural and political activity, as framed and mitigated by an equally diverse nature. Here, private experience of the individual is equated with the incremental (and therefore private) environmental processes 
which combine to affect significant change over the physical landscape, including its artificial constructs.

In the absence of rendered imagery, private experience is communicated here, through the presence of touch. Processoriented minimalists Eva Hesse and Jackie Winsor are significant influences in this respect because both have favored labor intensive, hand manipulated solutions in the fabrication of their serial objects. The two artists' respective artworks exude a potent psychological intensity due to the evidence of the hand's presence throughout the creative process and the resulting subtle alterations of otherwise uniform works. Winsor's meticulously assembled boxes and nailed board stacks posses an intense devotional quality resulting from the obsessiveness of her labor practices while Hesse's aggressively tactile experiments with fiberglass and latex modular units, assume the transparent unevenness of flesh. Hesse's work in particular is relevant here, because of its equation of surface with the body:3 Similar to an $x$-ray's exposure of one's internal vulnerability, the three works of this exhibition utilize transparency, in part, to maintain an awareness of the body's transience and eventual mortality.

Touch is manifested in various approaches to the individual works here, but the predominant characteristic in each, is a repetitiveness of action. In each work, a method of procedure is established, based on an existing system of order (a mainstream 
application of the grid), that is carried out over a duration of time until an internal content begins to emerge through the evolution of the materials. With respect to organic process, chance occurrence of some type has been built into that work procedure, thereby dispersing control over the outcome of the work between the materials handling of the artist, the social context of the existing system of order, and the internal logic, or nature, of the process itself. 


\section{I}

The News is Reticent is the first in the sequence of works and most clearly identifies the relationship of the whole to the discipline of painting. This work consists of a series of seven banner-like vertical panels of clear vinyl sheeting, painted on the reverse and hung side by side in tight formation such that the mass of the combined surfaces read continuously as an uninterrupted horizontal band. Within the group, however, individual panels are pigmented with distinct monochromatic hues that establish marked variations in color and contrast between successive surfaces. Each panel is further defined by a combination of one or more window-like, transparent rectangular openings of differing dimensions that reveal a murky view, through the vinyl material, to the underlying wall. Seen as a whole, the horizontal band of panels can be regarded either as a voluminous facade filled with windows or, because of the orderly, centered relationship of those rectangular openings from panel to panel, a negative spatial backdrop for what resembles a skeletal diagram of a salon-style arrangement of pictures.

As mentioned, those openings are, in fact, the negative impressions of the cover pages of assorted newspapers, dampened, unfolded and applied as stencils to mask out acrylic paint as it is rolled in successive layers onto the vinyl. The 
openings conform exactly to the exterior dimensions of the unfolded pages, including impressions of the perforations in the paper from the printing registration process, along with evidence of the characteristic scalloped borders that occur when the newsprint is cut. As a result, the rectangular openings are quite specific and they differ considerably from representations of pure geometric form. Their difference in size reflects the various formats of the newspapers employed, which emerge from a wide range of national, regional and local publications. Alluding to the aesthetic/cultural issue of diversity, the individual newspapers were selected to demonstrate a geographical and cultural crosssection of the United States that incorporates mainstream, community and special interest categories of information.

The format within each vinyl panel is determined according to the basic classification of the newspapers. Examples of national papers such as the Wall Street Journal, New York Times and USA Today are included together on one panel because of their general availability at most mainstream supermarkets or newsstands. Like the Times and Journal, the Christian Science Monitor and Washington Post are considered papers of record, but their distribution is not as widespread and their publishing circumstances are more unique: therefore, each occupies a separate panel. Groupings according to region are present in a panel including the Los Angles Times and The San Francisco 
Examiner. In continuum, combinations of that type proceed on down to very local and specific communities.

The identities of these papers would not be at all apparent except in some instances were the print has left ghost impressions of ink on the vinyl. This feature cannot be controlled in any way, but is, instead, a chance result of the painting process: depending on the density and general chemistry of the ink from the newsprint, it sometimes transfers when it is dampened and pressed against a slick surface. Chance was deliberately built into the work so there would be enough evidence of the source of those impressions to engender awareness in the viewer, yet the image would escape literal replication. The specificity of its content is not so important as is the recognition of the newspaper as a purveyor of information and the history of its inclusion in the painting process.

Performing like a map's legend, a panel hangs adjacent to the larger grouping which contains a master list of all the newspapers represented in this configuration. The list includes the masthead of each paper in its original typeface and is arranged so that it corresponds to the sequence of the seven panels as they are read left to right. The inclusion of the legend is necessary in order to communicate the geographical and anthropological make-up of those informational sources. The legend reads in the following order: 
Christian Science Monitor

The Wall Street Journal

The New York Times

USA Today

The Washington Post

San Francisco Examiner

Los Angeles Times

The Oregonian

Seattle Post-Intelligencer

El Hispanic News

The Asian Reporter

Single Christians Newsletter

Just Out

World Weekly News

The National Inquirer

Globe

Star

Sun

While this collection of Newspapers is by no means comprehensive, it does suggest a progression in the sources of information from macrocosm to microcosm. Last are the tabloids, which, as a group, host large and diverse circulations, but deal with a type of information that, while perhaps based on factual material, is in large part fabricated or embellished. This final group is largely concerned with personal discretion rather than public record and it therefore underscores the general fictional character of this work as a whole, in the absence of concrete 
information other than what is apparent in its physical appearance. Here, there is no attempt to evaluate or prioritize news sources; rather, the newspapers are grouped according to what could be considered common sense associations.

Through the history of its use in the realization of previous works, the continued use of newspaper as a working byproduct has acquired so much significance, it has inevitably become the subject. Newspapers are special markers of time--their ubiquitousness in stacks and bundles throughout the landscape and oppressive proliferation within the home as refuse, expose time as physical substance. The presentation of its residue in this work, without body or substance, speaks about the nature of its obsolescence once immediate facts have been reported and usurped by the following day's news. It is, therefore, a record of mortality. Describing the news as "reticent" is a verbal pun relating to the voids in those vinyl banners where information would normally appear and the inability of so-called impartial reporting to supply a complete and accurate picture of cognitive experience.

This work is also a reflection on the passing of information--the inability of language to communicate all aspects of experience. The voids which take up the central space in each of those panels rely on their painted margins to supply body and substance to the art. The work's implication is that real information comes 
from within those margins, or the periphery, as in scientific inquiry, and is a result of careful, objective scrutiny. 4

Like the first work, Preternatural Rhythm has also evolved out of the byproducts of the working process. It is the result of a compilation of consumer images regularly clipped from newspapers and magazines over the last decade from the standpoint of a fascination with craft and function.. The collection process was of a passive nature and encompassed the types of sources that would ordinarily cross an individual's path without special solicitation. Eventually, the images were grouped according to subject and stored in a file similar to an editorial cartoonist's "morgue." Over time, having repeatedly been filled with material from the same sources, the files began to reflect the evolution of particular items, resulting from commercial needs to continually improve and expand upon marketable products. This process was compelling in its similarity to Darwin's themes of variation and natural selection within the plant and animal kingdom.5 Eventually, the contents of the files came to be regarded as specimens similar to the organisms a naturalist would collect from forays into the field.

One of the more compelling examples of the collected consumer objects was the image of the stationary exercise machine. As an icon of contemporary western culture, the ubiquitous apparatus makes an especially potent symbol to epitomize physical 
experience in the age of telecommunications. It is engineered within the current technological drive to flatten spatial perimeters and compress experience for the benefit of time saving efficiency. It mimics human locomotion, but incorporates devices to compound muscle tissue and reduce fat while allowing its user to perform additional functions, thereby making its use more desirable than the actual movement it simulates. Nearly every commercial publication, regardless of its discipline, features advertisements of variations on this apparatus, so that it is fixed in our landscape as are computers and automobiles. Fittingly, in service to this exhibition, it appears an excellent transitional symbol between artifice and life.

Images of figures operating those machines occupy the central row of this gridded, multi-segmented piece, which is composed of more than one hundred forty notebook sized sheets of transparentized papers and fabrics, predominantly patterned with an assortment of organic and floral motifs (a mechanized landscape suitable for the machine). The individual sheets are hung in vertical format and stacked in three horizontal rows spanning the width of fifteen sheets, proportionally filling the length of the wall. Each sheet is perforated on its upper margins with two punched holes and hung, up to four layers thick, on white, ball-capped push pins. To simulate the rhythmic groove of the machine in operation, individual sheets are arranged to allow for the greatest possible transparency between overlapping 
surfaces, revealing a tempoed uniformity of pattern, that pulses from underneath as well as from page to page.

Unlike the paper and fabric of the other surfaces, the exercise machines are copied onto clear mylar to allow the underlying layers of pattern to show through. They are printed in black and despite their higher contrast, remain contiguous with the overall surface because they are integrated into the layering process along with the rest of the materials. Like the patterned fabric, there is a randomness about their presentation. Because of the way they are arranged on individual pages, according to the most economical means for copying, they appear retrofitted like interlocking components, in defiance of the gravity that representational images would otherwise suggest.

In this work, the significance of the machine lies in its repetitive function. As in the fabrics, where an organic motif has been woven into a fabric grid, the exercise machine represents a similar natural process, adapted in a mechanistic way. Both phenomena embody a desire to harness nature and order it artificially. In the case of the machine, the desire is to improve one's physical conditioning, to make the body more compatible with nature and at the same time, to defy it by prolonging life. Floral patterns and botanical designs similarly celebrate natural fecundity while they simultaneously attempt to sanitize and control it within the domestic confines of culture. 
In a secular culture, exercise and experience of nature become alternate forms of worship. This work intimates a type of spiritual questing that comes through repetitive acts--a desire to literally transform the body and release it from physical confines. The myriad grids within grids of the format, embody the compulsive nature of an athletic workout and the ritualistic repetition of prayer. The conflict in this work lies in the static nature of the machine. There is an entropic quality about so much energy spent on movement which does not encompass the crossing of actual space.

In relation to the gridded representations of like objects such as the exercise machines, the work of German photographers Bernd and Hilla Becher is especially significant. The Bechers began documenting the post-war ruins of Germany's architecture in the late $1950 \mathrm{~s}$ and have since gone on to systematically catalog the edifices of the industrial revolution throughout Europe. The artists employ gridded formats ranging from two to twenty images, in grouped typologies of individually photographed structures that perform similar if not identical functions. The images are pictured frontally, without distortion or dramatic lighting, and the clarity that emerges under such conditions allows the subtle variations within each structure or machine to emerge without esthetic bias, similar to the presentation of a scientifically detached entomological display of related bugs in the natural history museum. In this respect, the Bechers 
successfully straddle the division between aesthetics and functional application, as it pertains to systemic grids, a quality the work of this exhibition similarly attempts to engender through its repeated references to both poetic and pragmatic solutions .

If the contradictory tendencies of Preternatural Rhythm implies stasis, it nevertheless provides a continuum between the first and third works through its reference to movement. Camouflaging Sequence is the last work of this series and it attempts to summarize, through actual physical embodiment, issues that were introduced in the first two works: Nature is alluded to in The News is Reticent through chance occurrences in the working process. It finds representation in Preternatural Rhythm, in the stifled gridded armatures of floral prints. Here, nature is fully realized and allowed to proliferate through the presence of assorted organic materials, pressed and methodically encased between transparent sheets of tissue. Once again, the form of this work has been dictated by the residue from other projects and that residue has been recycled into this work along with newly acquired ingredients.

Recalling a collage process applied in previous works, disparate materials such as clothing, found photographs and paper were assembled in the studio, like tools or paint, for practical accessibility, and pinned to the wall in rows according to category 
and usage. As the materials were cycled in and out of the art, their display on the wall assumed a deconstructed character as a result of frequent cutting, shaping and sectioning off, becoming ever more fragmented and farther removed from their original function. Those fragments grew into hanging stacks, sorted by size, transparency or color relationships where, like organic putrefaction, they began to reflect the disintegration and comingling of once discreet objects. Camouflaging Sequence implements those stacks of fragments as a similar device for sorting and integration, while it provides a lineage between artificial and natural polarities.

With this final work, the grid departs from its uniform appearance and assumes a stuttered regularity, its segmented components varying greatly in size and proportion due to their inadvertent history. Its only even dimension is along the top margin where the numerous stacks and fragments emerge from a horizontal metal carpet rail. Cognizant of the presence of gravity as an undermining force, the individual pieces dangle loose and uneven at the bottom, subject to eventual dematerialization. Moving from end to end, the work is punctuated at intervals by large, concentrated clusters of transparent surfaces that consist of plastic tarpaulin and glue impregnated tissues, imbedded with an assortment of clothing articles, fabric fragments, insects, leaves, pressed flowers and vines. 
There are four such clusters in the whole of the work and each hosts a predominant material: On the left hand side are the clothing articles, still intact, revealing the human form. As the sequence moves to the right, the clothing loses its contours and becomes increasingly fragmentary until only fabric swatches remain. A similar process takes place from the right margin where the organic materials dominate and then become fragmented and depleted. In the middle, where the opposing materials converge and interact, the adjacent clusters appear visibly crowded with indecipherable fragments, each tipping in one direction or the other, toward its defining substance. Viewed in the context of the other works, Camouflaging Sequence is part of a linear progression that should read from left to right rather than from convergent poles. Therefore, its internal progression leads from artifice to organic substance, where the former is eventually usurped.

If Camouflaging Sequence is the most visceral of the three works, it is also the most conceptually literal, so it requires less nuance in discussion. Its subtleties exist within a complex surface that undergoes a distinct transition between the man-made and the natural. The preceding works lead up, in degrees, to this work's physical manifestation which, in turn, reflects a philosophy prioritizing science and the observed world. Within a physical realm, absent of intervening religion, decay and putrefaction lead to the basis for renewal. 


\section{I I}

The preoccupation of this work, as a whole, with the intricacies of process and its determination to present itself through preexistent cultural models and even its own working byproducts, leads back to its initial identification with the principle of democratizing content. Similarly, its repeated references to transience and decay come in the interest of leveling otherwise impenetrable social hierarchies. The subtlety of this enterprise is necessary because there is simply no other means to bring into focus, the significance of peripheral things. Its concern with disparate materials and sources of information is apparent, but the work stresses integration rather than isolation and disjunctiveness--it therefore lacks jarring contrast.6 The problem this work most thoroughly engages itself with then, is in making itself visible through intensity of touch. 


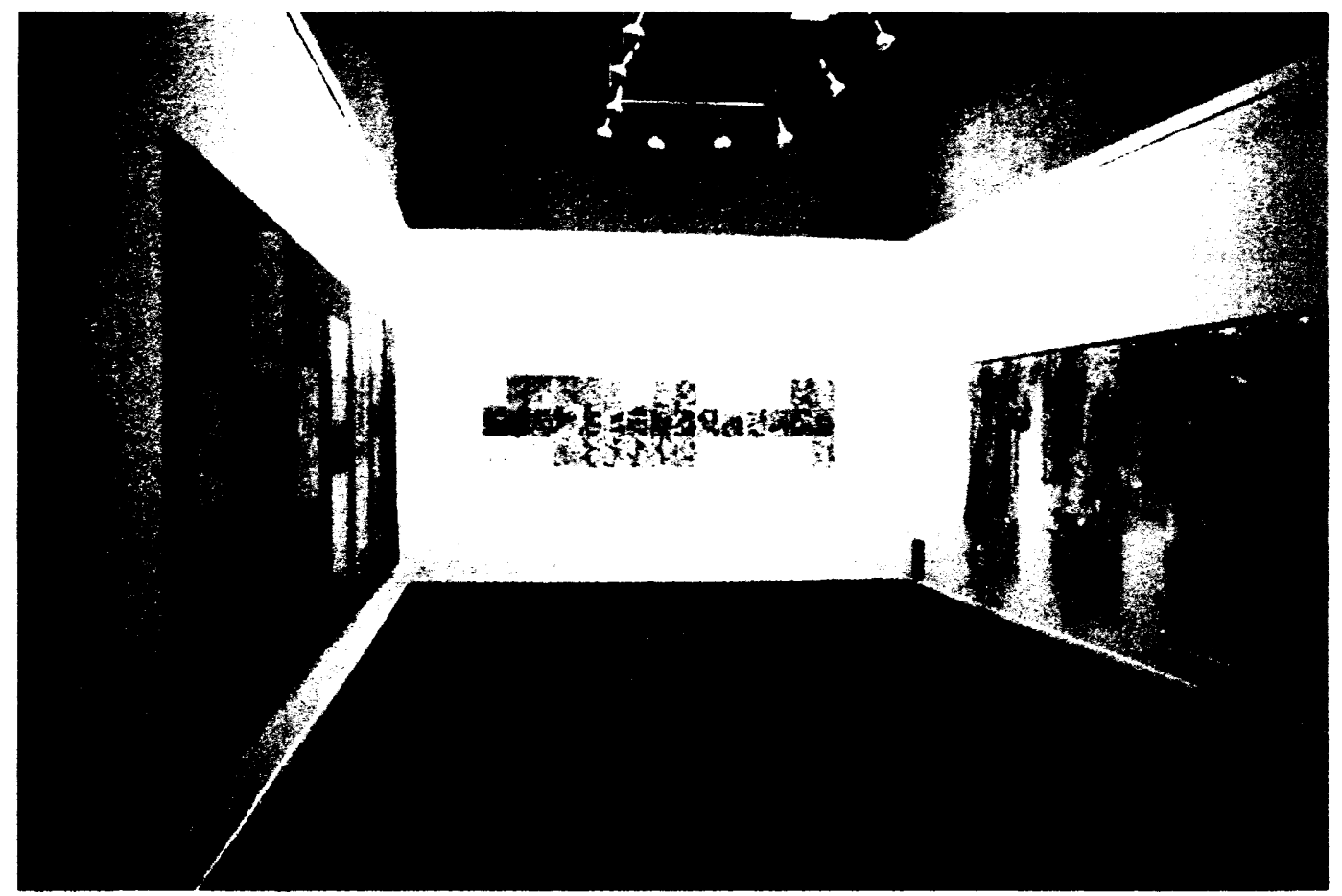

View of installation 


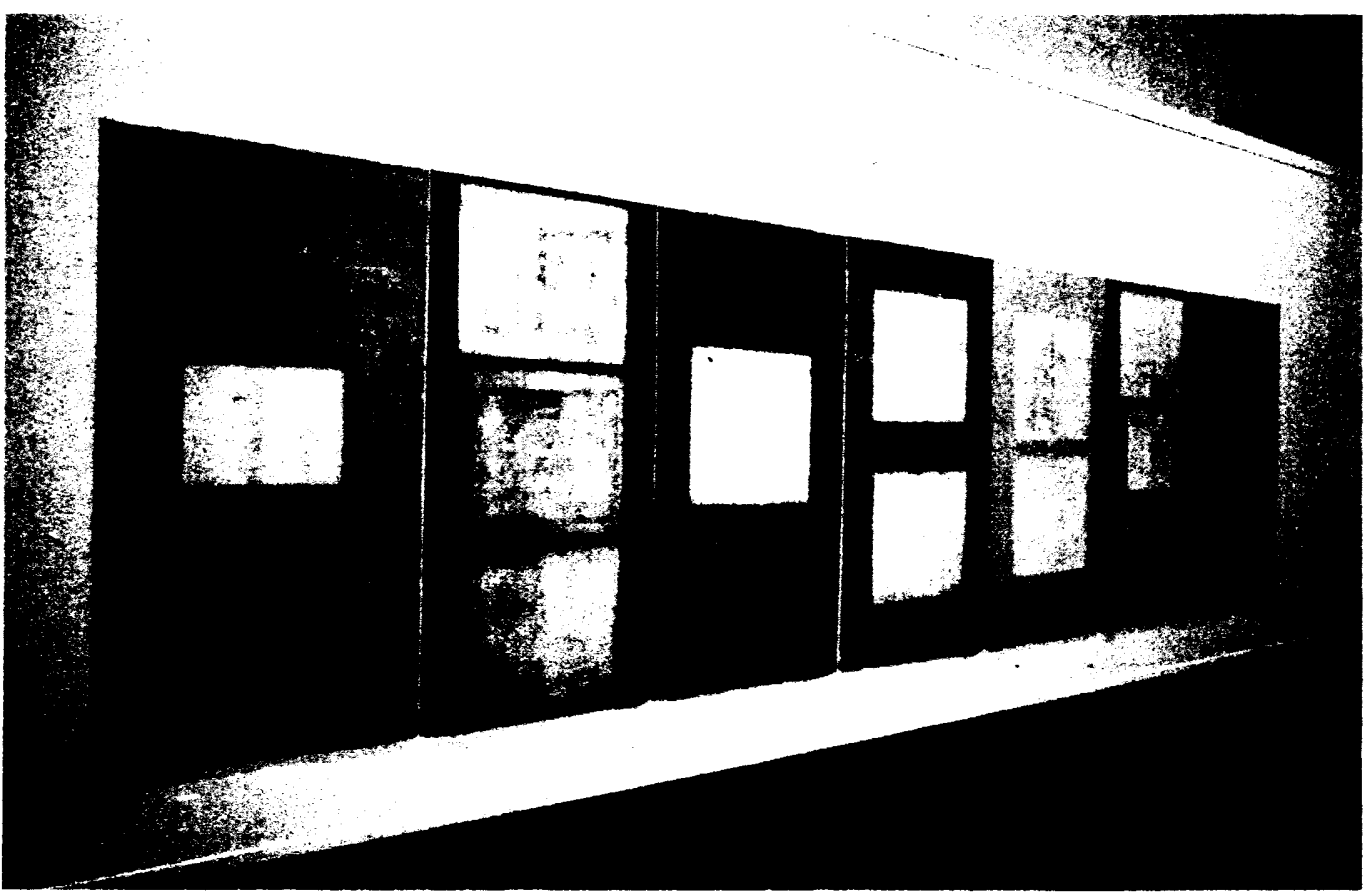

The News is Reticent, 1997

Acrylic and traces of printing ink on vinyl

$72 \times 300$ in. overall 


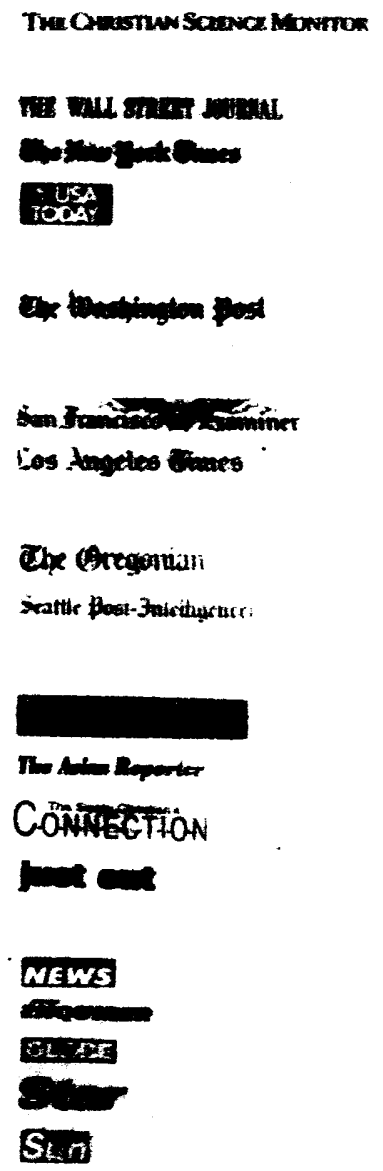

The News is Reticent, 1997

(detail of newspaper legend) 


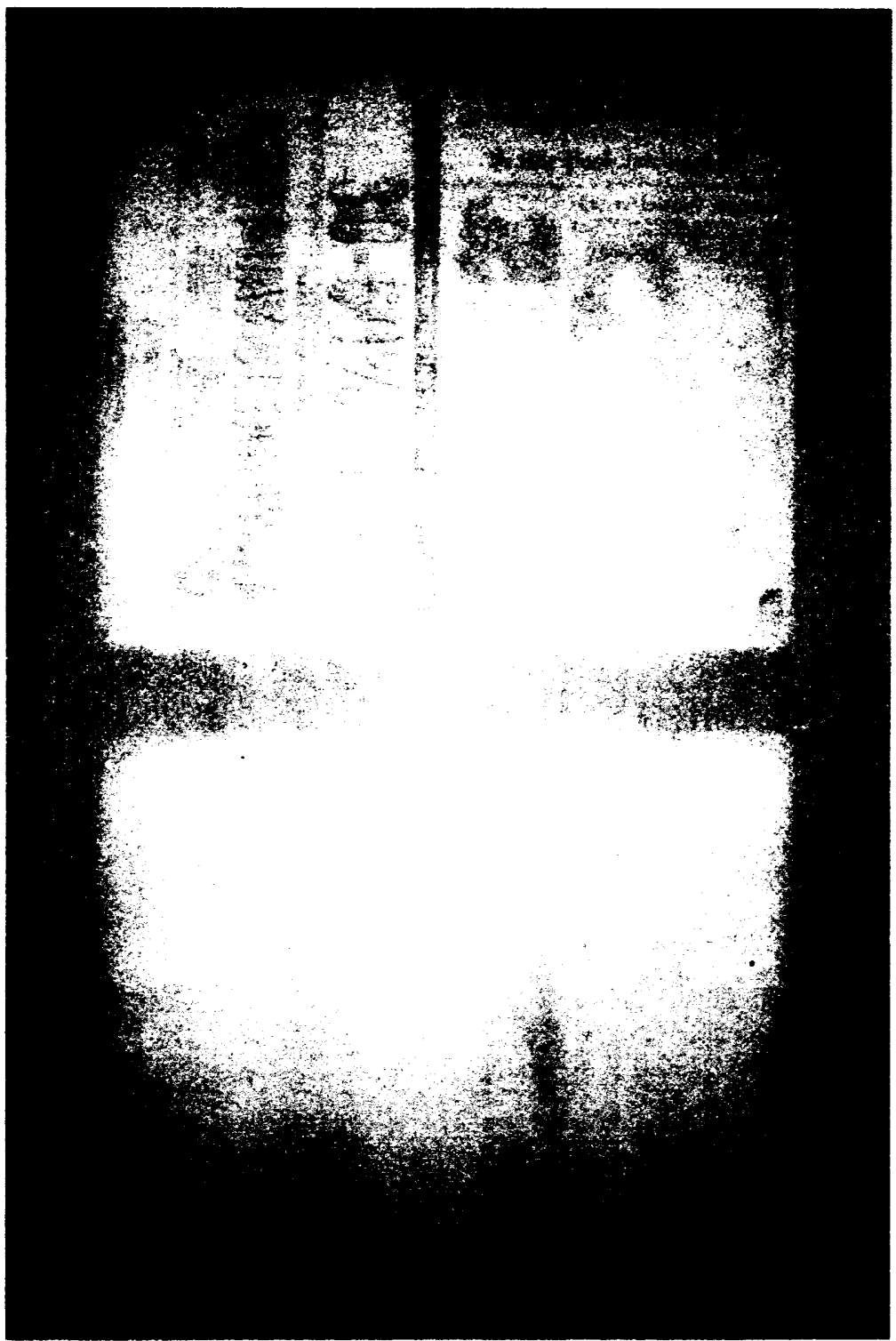

The News is Reticent, 1997

(detail of panel bearing impressions from The Seattle PostIntelligencer and The Oregonian) 


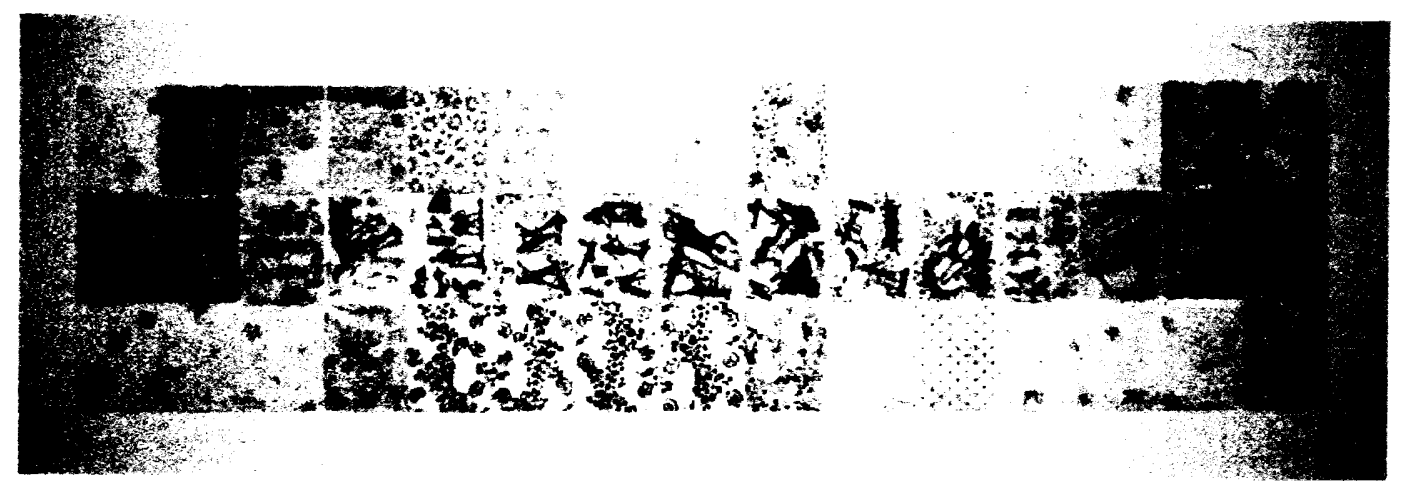

Preternatural Rhythm, 1997

Fabric, plastic, paper and photocopies on mylar $33 \times 127.5$ in. overall (dimensions variable) 

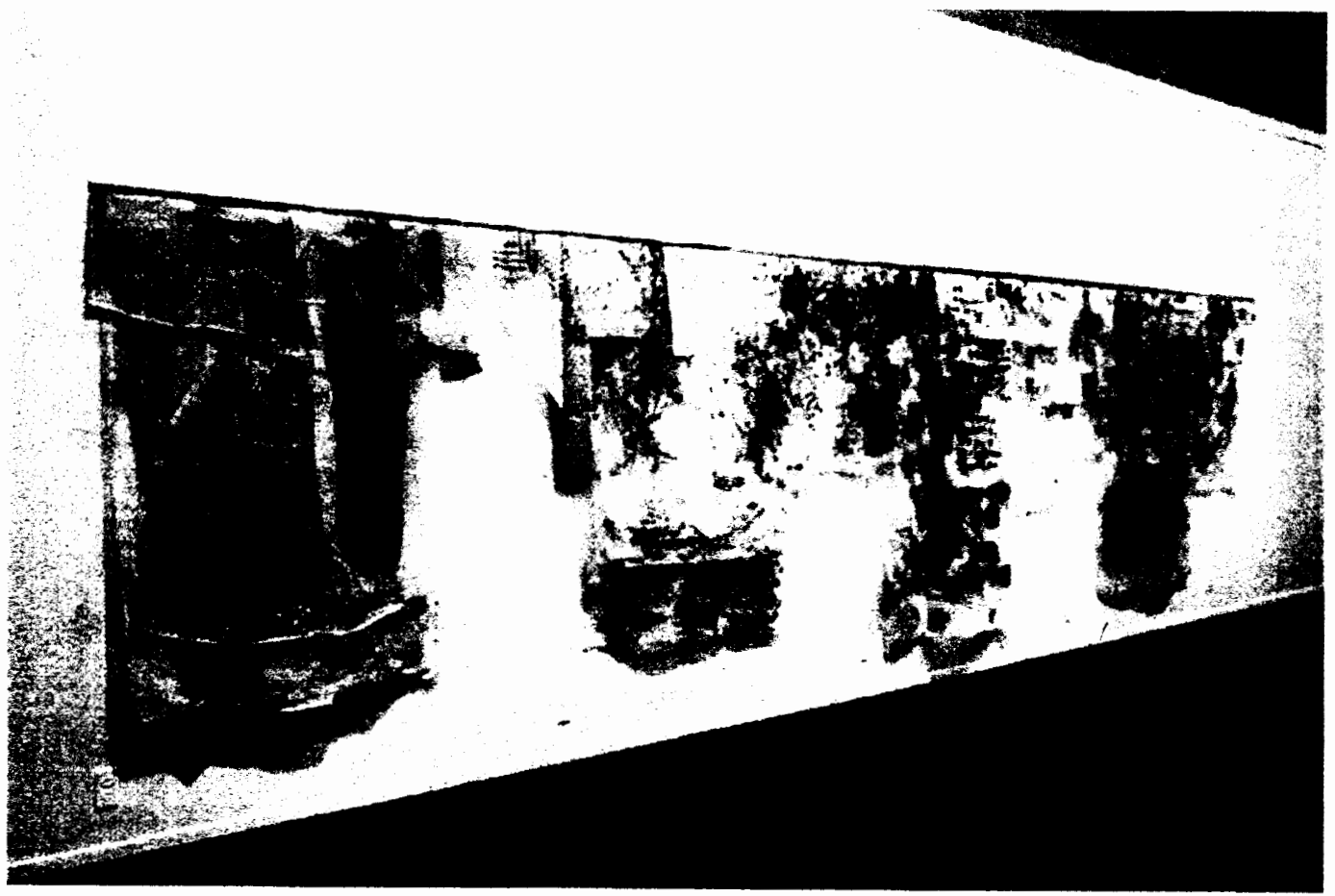

Camouflaging Sequence, 1997

Printed fabric, articles of clothing, organic substances and metal 74 x 306 in. overall (dimensions variable) 


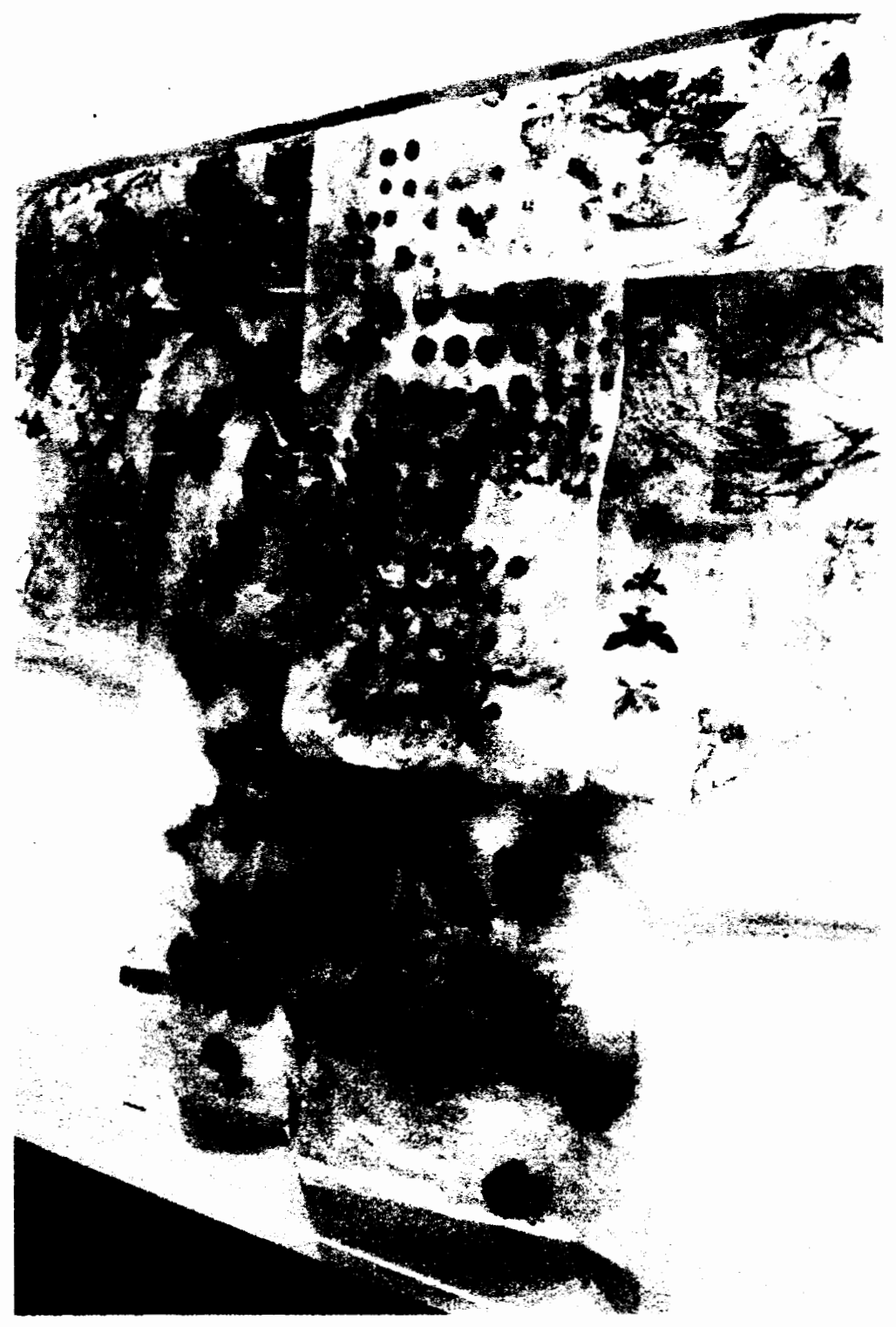

Camouflaging Sequence, 1997

(detail of organic substances) 


\section{ENDNOTES}

1. Robert Rauschenberg has referred to his art as inhabiting the "territory between art and life." This work shares an affinity with that concern in its collage approach to process and incorporation of real objects. But it departs from Rauschenberg's methodology in its attitude towards content. Rauschenberg's process stresses the physical substance of his objects where this work attempts to straddle the definition between objectness and epehemera in pursuit of a specific symbolism.

2. For discussions pertaining to cultural diversity and the prominence of identity in contemporary art, see the written essays in The Decade Show catalog, produced in conjunction with a collaborative exhibition between The New Museum of Contemporary Art, the Museum of Contemporary Hispanic Art and The Studio Museum of Harlem, all of New York City. The exhibition features current work integrating personal with political issues from a broad cultural spectrum of artists.

3. In her monograph on Eva Hesse, Lucy Lippard is careful to point out that Hesse took great pains to avoid anthropomorphizing her work. The resemblance to human form and flesh, she points out, results from the artist's profound identification with her materials. Lippard further states, "Hesse's existential humor and her eroticism meet and merge not so much in the shapes themselves (which in the earlier pieces overtly resembled breasts, limp phalluses, etc.) but in the combination of shape and highly sensuous textures, the way forms swell or sag, lie or lean, the ways in which one can feel one's own body assuming those positions or relating to those shapes as to another body."

4. An excellent example of this type of observance of the periphery is in Darwin's twenty year study concerning the dominant role played by earthworms in the creation of the earth's topsoil as discussed in Steven J. Gould's essay Worm For All Seasons and a Century in his collection of essays Hen's Teeth and Horse's Toes. Darwin's Origin of Species is, of course, the reigning monument to careful scrutiny, where his 
manifold descriptions there, flow into one continuous, hypnotic monologue on minutiae in support of his overall premise.

5. This statement was made in awareness of the 19th century mercenary capitalist phenomenon of Social Darwinism. Here, with some facetiousness, the statement in the text attempts to subject those sophisticated, culturally driven consumer marketing practices to the more elemental and omnipotent processes of nature.

6. As a means of a cultural dialogue and critique, much visual art of the postmodern era juxtaposes highly contrasting and sometimes oppositional or contradictory images, materials or processes to emphasize the presence of multiplicity, cultural dysfunction, the merging of high and low culture, etc. (See the work of Bruce Nauman who has been particularly influential among the current generation of subtle integration of similar components through its identification with incremental organic processes. Through this method of presentation, there is potential for a type of seduction that leads deceptively into critique and dialogue. For a discussion on the role of painting in postmodern culture, see Thomas Lawson's essay, Last Exit: Painting, in Art After Modernism: Rethinking Representation. 
BIBLIOGRAPHY

Darwin, Charles. The Origin of Species. First Edition, November 24, 1859. New York and Scarborough, Ontario and London: The New American Library of World Literature, Inc. 1958

The Decade Show: Frameworks of Identity in the 1980s. New York: Museum of Contemporary Hispanic Art, The New Museum of Contemporary Art and The Studio Museum in Harlem. 1990

Gould, Stephen Jay. Hen's Teeth and Horse's Toes. New York and London: W.W. Norton and Company. 1983

Imi Knoebel. New York: Dia Art Foundation. 1987

Krauss, Rosilind. "The Originality of the Avant-Garde: A Postmodern Repetition." Art After Modernism: Rethinking Representation. New York and Boston: The New Museum of Contemporary Art and David R. Godine. 1984, p. 13-29

Lawson, Thomas. "Last Exit: Painting." Art After Modernism: Rethinking Representation. New York and Boston: The New Museum of Contemporary Art and David R. Godine. 1984, p. $153-165$

Lippard, Lucy. Eva Hesse. New York: New York University Press. 1976

Lippard, Lucy R. Get the Message? A Decade of Art for Social Change. New York: E.P. Dutton. 1984

Sandler, Irving. American Art of the 1960s. New York: Harper and Row. 1988

Wilson, Alexander. The Culture of Nature. Cambridge, Massachusetts: Blackwell Publishers. 1992 